\title{
Nutrition Therapy and Treatment of Diabetes Mellitus
}

ISSN: 2578-0263

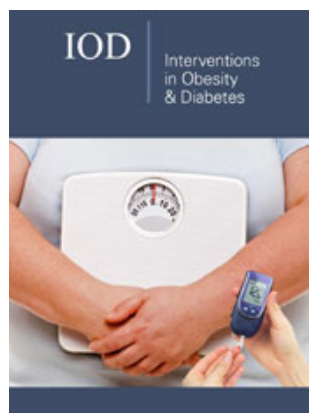

*Corresponding author: Dietitian Ayesha Mushtaq, dietitian and counselor, Pakistan.

Submission: 侮June 10, 2019

Published: 祭 June 27, 2019

Volume 3 - Issue 1

How to cite this article: Dietitian Ayesha Mushtaq. Nutrition Therapy and Treatment of Diabetes Mellitus. Interventions Obes Diabetes. 3(1). IOD.000554.2019. DOI: 10.31031/IOD.2019.03.000554

Copyright@ Dietitian Ayesha Mushtaq, This article is distributed under the terms of the Creative Commons Attribution 4.0 International License, which permits unrestricted use and redistribution provided that the original author and source are credited.

\section{Dietitian Ayesha Mushtaq}

Dietitian and counselor, Pakistan

\section{Opinion}

Endocrine glands that make up the endocrine system are not attached anatomically but scattered all through the body. All the same, these glands make up a system in a functional sense. Functions are carried out by secreting hormones (chemical messengers) into the blood, and numerous interactions occur between the various glands. Over 20 million individuals in the US have Diabetes Mellitus. According to some researches and survey, it was estimated 14.6 million have been diagnosed, but 6.2 million are unaware they have the disease. By far the most common of all endocrine disorders, and a worldwide health problem, diabetes mellitus is not a single disease but a diverse group of disorders that differ in origin and severity. Yet all forms of diabetes mellitus share one common characteristic: hyperglycemia resulting from defects in insulin production, insulin action, or both. Chronic Hyperglycemia is correlated with longterm damage, dysfunction, and failure of numerous organs, particularly the eyes, kidneys, nerves, heart, and blood vessels. Insulin deficiency is generally due to either insufficient insulin secretion by beta cells or comparative deficient response by target tissue cells to insulin. Whatever the cause of insulin deficiency, it results in glucose intolerance was used by the expert committee on the diagnosis and classification of diabetes mellitus to diagnose and classify diabetes. Medical care of diabetes mellitus should be the coordinated effort of a team with expertise and a special interest in diabetes. The team should be compromised of individual with diabetes and the following care providers. And that the goals and treatment are reasonable. Type 1 diabetes mellitus (T1DM) accounts for $5 \%$ to $10 \%$ of all diagnosed cases of diabetes approximately 400 to 600 children and adolescents have T1DM. Immunemediated type 1 diabetes mellitus results from cellular-mediated autoimmune destruction of b-cells of pancreas. While type 2 is common in adults and was previously called non-insulin diabetes mellitus (NIDDM) or adult-onset diabetes, but these terms perfume a disservice to individuals with diabetes, because they classify them by treatment modality rather than disease characteristics. There is no one "diabetic diet" or "ADA diet" even though the term "ADA diet" has never been clearly defining, in the past it usually meant a physician determined kcal level with explicit percentages of carbohydrates, protein, and fat based on the exchange lists. The American Dietetic Association (ADA) recommends the term "ADA diet" not be used since the ADA no longer sanctions any single meal plan or specified percentages of nutrients. Nutrition therapy is an essential element of glycemic control and diabetes self-management education (DSME). A comprehensive nutrition assessment, self-care treatment plan, and the client's s health status, learning ability, readiness to change, and current lifestyle should be the basis for nutrition therapy and DSME. 